\section{Huang Di Nei Jing Ling Shu; The Ancient Classic on Needle Therapy; The Complete Chi- nese Text with an Annotated English Translation}

\author{
Boaz ItsHaky* \\ Acupuncture Institute, University of Bridgeport, USA
}

\begin{abstract}
This article includes the introduction section from the book "Huang Di Nei Jing Ling Shu; the Ancient classic on Needle Therapy; the complete Chinese Text with an Annotated English Translation" by Paul U Unschuld and with a preface by Boaz ItsHaky.

We now have a new English translation of the Huang Di Nei Jing Ling Shu from the esteemed scholar Paul Unschuld. Initially approached for a commentary about his new translation, professor Unschuld replied that perhaps the best 'commentary' would be the publication in the Journal of Alternative, Complementary \& Integrative Medicine of the introduction section of the book.

Professor Unschuld is the founding director of the Horst-Goertz-Institute for the theory, history and Ethics of Chinese Life Sciences at Charité-Universitaetsmedizin Berlin in 2006. Over the past decades he has written extensively about Chinese medicine, and thanks to his efforts all three classical Chinese medical texts are now available at a scholarly level in English translations.

In 1986 Unschuld's published his first translation of the "Nan Jing: The Classic of Difficult Issues", which he has updated and published its second edition in June 2016.

In 2011 he published together with Hermann Tessenow the English translation of the "Huang Di Nei Jing Su Wen; Huang Di's inner
\end{abstract} classic; basic questions".

In June 2016 at the time of the appearance of his second edition of the Nan Jing (see above), Unschuld has published the "The complete Chinese Text with an annotated English translation: Huang Di Nei Jing Ling Shu; the Ancient classic on Needle Therapy" (the second volume of the Huang Di Nei Jing). Its user friendly design allows for a fluid read and easy comparisons between Chinese characters, the English translations and the commentators.

I would like to thank Unschuld for his generous permission to reprint the introduction section of the book. As well, I hope that in the

"Corresponding author: Boaz ItsHaky, Acupuncture Institute, University of Bridgeport, USA, Tel: +1 2035370699; E-mail: boaz.itshaky@gmail.com

Citation: ItsHaky B (2017) Huang Di Nei Jing Ling Shu; The Ancient Classic on Needle Therapy; The Complete Chinese Text with an Annotated English Translation. J Altern Complement Integr Med 3: 020.

Received: December 13, 2016; Accepted: February 02, 2017; Published: February 16, 2017 future we will be able to clarify with him some other "difficult issues". For example, why he has decided not to allocate an English equivalent to the term and concept, to which is Qi.

Following below is the introduction section of "The complete Chinese Text with an Annotated English translation; Huang Di Nei Jing Ling Shu; the Ancient classic on Needle Therapy", as it appears originally in the book and without any editorial changes.

\section{Introduction}

\section{A new world view, a new healing}

The Ling shu 霉樞, also known as Ling shu jing 霉樞經, is the classic text on acupuncture. Much of the version known today probably dates back to individual, shorter texts that began to be written between the $2^{\text {nd }}$ and $1^{\text {st }}$ centuries BCE during the two Han dynasties of Ancient China. The authors of these texts are unknown, as is the individual who, at some point in that time, collected the individual texts into one great work.

Many questions surrounding the origins of the Ling Shu remain unanswered to this day. A bibliography by Liu Xin 劉歆 (Died 23 CE) from the early years of the $1^{\text {st }}$ century mentions a text titled Zhen Jing 針經, “The Needle Classic," consisting of nine chapters. Liu Xin supposedly based his work on an older catalog with the title Bie Lu 別錄, compiled by his father Liu Xiang 劉向 (Died 6 BCE). The extent to which the content of the Ling Shu available today is identical to this Zhen Jing can no longer be ascertained with certainty. It is likewise unknown who ultimately gave the work the title Ling Shu, or "The Numinous Pivot", which bears no relation to the content of this text, marked as it is by explicitly secular reasoning. Perhaps it was the physician and Su Wen 素問 commentator 王冰 Wang Bing, who used the title Ling Shu for the first time in the $8^{\text {th }}$ century CE. All we know for sure is that the content of the Zhen Jing cited by Huangfu Mi 皇甫 䛑 (215-282) in his medical classic Jia Yi Jing 甲乙經 is also present in its entirety in today's Ling Shu. The commentary that Huangfu Mi assigned to the text in the foreword of the Jia Yi Jing is remarkable: "Today there is a Zhen Jing in 9 juan and a Su Wen in 9 juan. 9 plus 9 equal 18 juan. It is partly lost. The tracts it contains reach back to distant times. However, the text consists mainly of allegations and has only limited practical value".

None of the authors whose texts constitute the Ling Shu were thinking of magic or numinous powers. Indeed, for the time the Ling Shu was a revolutionary work in the true sense of the word. Together with its sister works the Su Wen and Nan Jing 難經, it represents an explicit counter model to the prevailing image of the world at the time, which regarded human life as subject to extreme degrees of existential alien influence. Deities, demon spirits and ancestors in addition to "the heavens" as a numinous power held sway over the ups and downs of each individual. In general, people believed that the duration and quality of life on earth were not under their own control. The authors whose thinking has found expression in the texts handed down to the present day in the Su Wen, Nan Jing and Ling Shu were a group of intellectuals whose names and number would very quickly be forced into the darkness of collective forgetting and with good reason. They questioned what had for many centuries remained self evident for all 
segments of society. They confronted their contemporaries with the idea of natural laws that were valid regardless of deities, spirits, demons and ancestors, not to mention of time and space. These intellectuals constituted the kernel of an enlightened, secular perspective on the world, the consequences of which would open up a view of nature and the embedding of humanity in the laws of nature as a foundation for understanding the origins, essence and transience of life.

By this time China was already a highly advanced civilization. A complex state administration with a bureaucracy that ensured continuity as well as social and economic standards was accompanied by a culture of writing that addressed the numerous themes of daily importance in this state construct. Libraries and catalogs took note of works composed either as chronicles or philosophical texts, as dictionaries or military guides. Many of these authors are still known by their names. It might therefore seem puzzling why the authors of exceedingly large books that founded a new form of healing, a "medicine" in a modern sense, should not belong to this group. It might seem puzzling why their texts survived the centuries only as extremely fragile copies, or even like the Ling Shu and the Tai Su 太素 been mostly or completely lost even in China. One might explain these losses through the many wars that also caused the destruction of countless other manuscript texts, but this argument is not persuasive. Had the Su Wen, Ling Shu and Tai Su been esteemed by larger numbers of the educated elite, they would have been copied in sufficient quantities to become the foundation for responses to illness in these strata of the population. Yet, as all the evidence suggests, this was not the case.

Thanks solely to the fact that copies of the Tai Su were brought to Japan and survived for centuries there as fragments do we have the possibility today of laying our eyes on this oldest testament to all those ancient texts, one created from an annotated compilation of the content of the Su Wen and Ling Shu. The author of the Tai Su is Yang Shangshan 楊上善. His name is the sole one of the writers of the works that together and in hindsight is identified as constituting the Huang Di Nei Jing 黃帝内經, “The Inner Classic of Huang Di” text corpus. However, Yang Shanshan lived later, during the Tang dynasty in the $7^{\text {th }}$ century. That time witnessed a completely different atmosphere of never before seen diversity in world views. Yet even then, the Tai Su was apparently regarded as insufficiently important. The number of copies produced in China was too low to prevent the work from being lost in China itself.

In the centuries following the Han period, few authors took up the ideas of the revolutionaries. Best known is the aforementioned Huangfu Mi 皇甫䛲, writer of the Jia Yi Jing 甲乙經 in the third century. The extent to which the Jia Yi Jing and other texts continually handed down in China reproduced the content of the Su Wen and Ling Shu in a manner that obscured the "objectionable" character of the source texts is a matter for future research. Only in the $12^{\text {th }}$ and $13^{\text {th }}$ centuries, in the context of a fundamentally transformed view of the world, did the thousand-year shadow existence of the source texts come to an end. On the emperor's orders, the most important surviving manuscripts were edited and made available to the wider public. Lin Yi 林億, a collaborator in this editing project and publisher of a $\mathrm{Su}$ Wen edition from the year 1067, cited from a lost Ling Shu text and remarked in his foreword: "Today the Ling Shu is no longer available in its entirety." Moreover, the passages cited by Lin Yi do not match any surviving Ling Shu texts. In 1092 a version of the Ling Shu titled Huang Di Zhen Jing 黄帝針經, “The Needle Classic of Huang Di," was brought to China from Korea. Finally, a Song-era doctor named Shi Song 史崧, whose exact lifetime is no longer known, became the first to study the Ling Shu in depth and, in 1135, published an annotated manuscript from his personal family holdings. This edition has ever since been considered the Ling Shu that extends back to the Han era. From then on, historians began devoting themselves to questions surrounding the authorship and temporal origins of the Huang Di Nei Jing texts; new, annotated editions were produced to lend meaning to the texts, which in many parts had since become difficult to comprehend.

\section{Huang Di - the Yellow Thearch}

The question of Huang Di's significance in the compilation of the Su Wen and Ling Shu was discussed early on. Huang Di 黃帝 does not mean "Yellow Emperor", as one often reads today in popular literature. Di 帝 is a monarch among gods, a deified ancestor, the Thearch, and huang 黃 means "yellow" and stands for China. The Yellow Thearch, as per the current standard international translation, was the highest cultural and spiritual authority of ancient China, and there were countless texts in which supposed a dialog between Huang Di and one of his ministers or advisers placed the most valuable contributions to ancient Chinese culture as coming from the lips of this very same Yellow Thearch. This is also how the authors of the Su Wen and Ling Shu seem to have proceeded. Yet the appearance is deceiving. Huang Di is with one exception, when confronted by Lei Gong, the Duke of Thunder not a sage but an ignoramus in the field of medicine who wishes to be instructed. This instruction is marked repeatedly by the respect expressed by the dialog partners of Huang Di. They sometimes describe themselves as 細子 $\mathrm{xi} \mathrm{zi}$, or "shorty", or 小子 xiao zi, "little boy", and in one instance, in chapter 73, Qi Bo refers to Huang Di as 聖王 sheng wang, “wise king”. In sharp contrast, one also finds various reprimands, inquiries and refusals by the knowledgeable ones that put this Huang Di into a light far removed from that of an awesome Thearch.

A vivid example can be found in chapter 80 of the Ling Shu. Here, Huang Di describes how he becomes dizzy every time he climbs a tall building. He is so dizzy that he can move forward only when on all fours. How to imagine a Thearch who needs to crawl on all fours to cope with his dizziness? How to imagine a Thearch asking a question of a teacher, who then answers by saying there really are things that shouldn't be told to everyone? Only once, when the Thearch appeals to his interlocutor's conscience, does the latter acquiesce to answering the question (see chapter 64). In chapter 47, Huang Di asks a question to which Qi Bo, the knowledgeable one responds with a long, meandering discourse until Huang Di loses patience and tells Qi Bo that was not what he asked. The knowledgeable Shao Shi responds to an especially naïve question with surprise and reproach in chapter 79: "What? You, a Thearch, do not know the answer?" To be sure, Huang Di does not shy away from frank remarks either, as when a reaction to a statement by Qi Bo is placed on his lips: "All sick people already know what you are saying".

Perhaps these oddities alone sufficiently demonstrate the author's attitude of questioning authority. The Ling Shu, like the Su Wen, is devoted not only to the supremacy of natural laws, but the rule of law as such. It is a bid at liberation from arbitrariness not only that of the deities, demons and ancestors, whose motivations must ultimately remain beyond the grasp of mortals, but all arbitrariness, meaning that of earthly rulers as well. Laws Fa and nothing but, are the standards humans must conform to. 


\section{The new terminology}

Fa 法: We know nothing about the authors of the texts that found their way into the Su Wen and Ling Shu. Our knowledge is similarly deficient regarding the authors of the texts collected during European antiquity into the Corpus Hippocraticum. We do not know what resistance the authors in China faced in trying to spread their ideas. The concept of natural phenomena obeying laws was new and certainly disturbing to the majority of people for whom the existence of deities, spirits, demons and ancestors seemed perfectly obvious.

A new ideology requires language and certain terms that express its new values. Toward this end, the founders of the secular world view in Ancient China proceeded in the manner as it was, and remains, the most effective. Instead of inventing new terms that were new and unfamiliar to the wider public, they turned to familiar terms and gave them new meaning. The word 法 $f a$ is probably the best example. Originally it referred to the "example" and "model" of the sages of early history, whom all people were expected to emulate for their own benefit and that of society. During the Warring States period $\left(5^{\text {th }}-3^{\text {rd }}\right.$ century $\mathrm{BCE}$ ), increasingly large states emerged that required bureaucracies to remain governable. That was when the term fa also took on the meaning of social and criminal law. The fa achieved the status of a legal power and therefore it was no longer a matter of individual discretion whether to follow them. It became a duty. Whoever defied them had to expect punishment. In the view of the Legalists, strict obedience of the fa was the only guarantee of good conduct among people. Appealing to the kindness of people, which the Confucians considered effective, seemed inadequate to the Legalists. But in the new, secular view of the world, the meaning of fa was extended yet again. Nature, too, has its laws, which people would be well advised to follow. Doing so may not always be pleasant, but is always accompanied by the certainty that fidelity to the law will be rewarded with well being. Belief in deities, spirits, demons and ancestors rests on an uncertainty that seems to be constantly confirmed by the arbitrariness of the numinous powers. At least victims would tend to see matters this way. But the new secular view of the world suggested that it was in people's own hands whether to give themselves a long and healthy life or illness and an early death.

The groundwork was thereby laid for a completely new form of healing arts. We call this new kind of healing "medicine". Medicine is a healing art, but not every kind of healing art is medicine. The development of medicine in this stricter sense took place in Ancient Greece and soon afterward in China, after intellectuals had removed health and sickness from the religious view of the world. They regarded the laws of nature as the sole standard that decided over the well or ill being of each individual.

The medicine in this sense that appears to us in China for the first time in the Su Wen and Ling Shu constituted this new art of healing. It rested on premises that, within a relatively brief time span, appeared plausible to some intellectuals in both Ancient Greece and China: first, natural laws exist and have effects independently of time, space and individuals are they numinous beings or humans. Second, these laws can be recognized and put into words. Third, knowledge of these laws suffices to interpret all material and non material phenomena and processes, including health and illness.

No one should assume that this new medicine, as it was conceived, proved to be conspicuously more effective than the conventional healing arts of the time were, whether they were based on empirics, magic or belief in demons. Still, the authors of the texts introducing the new approach did not shy away from immediately putting up the highest possible barriers between the old and new thinking. The explicit demarcation from demon belief is one sign that the protagonists had more in mind than just creating a new healing art. The new medicine, based exclusively on thinking aligned with natural law, drew its legitimacy from a completely new outlook on the world, one that also carried a political message. From a historiographical standpoint, the emergence of this medicine in China raises numerous questions. The texts in the Su Wen and Ling Shu convey the impression that Huang $\mathrm{Di}$, who remains unknowledgeable except in one dialog with Lei Gong, is instructed by men unidentified in the more ancient sources available to us, yet who drew upon a tradition that had already existed long before. They refer to literature that Huang Di should have known, as a passage in the Su Wen makes clear. They cite statistics that reflect a time span of experience with many patients. Also, as the Ling Shu repeated documents, they identify the differences between "unrefined" (i.e., incompetent) practitioners on the one hand and capable users of medicine on the other. These are hardly the hallmarks of a completely novel approach.

Reading the dialogs, one realizes that this medicine had already been a long established method of healing and that only the honorable Yellow Thearch had hardly heard a thing about it and was therefore quite clumsy in his attempts to apply this medicine. And that was although in later centuries (probably only by the early Tang period), this Huang Di found at the beginning of the Su Wen was viewed as a man of extraordinary intelligence and broad learning. Resolving this contradiction is a matter that research has yet to undertake. In any case, we do not know of any Chinese sources that could legitimize the dialogs' claim that this medicine had long been in use. The individual who submits to the laws of nature can deduce how long and good his life will probably be. However, this conviction raised the question of which humans should thank for giving them life. This issue is answered very clearly in chapter 56 of the Su Wen and elsewhere:

\section{人以天地之氣生以四時之法成}

\section{ren yi tian di zhi qi sheng, yi si shi zhi fa cheng:}

"Man receives his life from the qi of heaven and earth. He reaches maturity through the laws of the four seasons".

This leaves no space for metaphysical beings to whom humanity might owe its existence. The Chinese version of an Enlightenment that already became visible there in ancient times led to a completely secularized view of the world and thereby a medicine as well which, however, very few people accepted. The secularization of "heaven" is recapitulated almost in passing in chapter 5 of the Ling Shu. Following a detailed exposition of how health and illness depend on the constitution of each individual and have nothing to do with the intervention of deities or spirits, there follows a brief summation:

此天之生命 - ci tian zhi sheng ming; “This is the manner in which heaven grants existence". Here, "heaven" is bared of any metaphysical identity; it is nature itself.

Ming 命: Along with fa, a redefinition of the term 命 ming was also needed. Ming originally meant "assignment" and "mandate". Human life, according to the hitherto accepted idea, was a mandate of heaven. Heaven gave it and could revoke it at any moment, and humans had practically no influence in the matter. That would change under the new, secular world view. The Su Wen and, less explicitly, the Ling Shu state repeatedly that human beings are part of a system of natural laws through which things emerge, grow and die within a more or less clearly predictable timeframe. Natural laws can be violated just as 
social laws can. Both acts result in punishment. The terminology of the Ling Shu leaves no room for doubt. Chapter for chapter, it stresses the importance of a behavior called shun 順, literally meaning "adapted". It is the opposite of a behavior called ni 逆, literally “violation". The entire human organism, its therapy and therefore human behavior as well, are marked by the opposition of shun and ni, of adapting and violating. Shun, i.e., "following" the appropriate current, promises life, while ni, or "opposition", means ruin. In chapter 33 of the Ling Shu the principle is reduced to a simple little mnemonic verse:

"Those who manage to adapt, survive. Those who indulge in violation go under".

The parallels between the two levels of socially desirable respect for moral guidelines and penal codes, and personally advantageous adherence to the laws of nature are obvious.

Shen 神: The most important among the terms to be redefined was, however, 神 shen, generally translated as "spirit" or "deity". It was, along with "heaven", an abstract, supernatural power and authority that decided human fates. The demons, ancestors, other spirits, the deities all these numinous powers were subsumed under the term shen. It was, in league with "heaven", the expression of the human being's existential heteronomy. The prayers and sacrifices of the living were directed toward the shen, always in the hope that these powers could be bribed with good things, emotionally moved by good words or perhaps frightened by appeals to even more powerful beings. Among broad sections of the Chinese people this attitude has survived into the present day. At the time it was a firm conviction for probably everyone. It was in opposition to this conviction that the new world view appeared, and within the new medicine.

The fundamental idea of this medicine is the reversal of dependency in the relationship. Spirits do not hold sway over humans. It is the human being that controls the spirits. The intellectuals who created the new world view did not make the mistake of asserting that there are no spirits. They offered instead a new interpretation of a familiar concept. It states that every person contains spirits that are harbored in the body organs. There they are "confined" in a sufficiently stable manner as long as enough resources are available to hold on to the respective spirit. Only once the resources of an organ have been used excessively and a state of depletion ensues can the hitherto confined spirit break out and do harm to a person. In other words, it is up to each individual to conserve one's resources so that the spirits remain confined in the organs. Doing so lays the foundation for existential autonomy.

An important and likewise new concept stood for these resources: qi. The pictogram of the characters for "rice" and "steam" formed only in the later Zhou or early Han period, i.e., the time in which the new medicine was also being conceived, refers to vapors of the minutest materials along with blood, are essential for the survival of the human body. The qi of an organ, i.e., its resources, are depleted most easily by the emotions. Undisciplined emotionality permits the excessive drainage of qi from the respective organ responsible for grief, joy, fear, etc., and leads to two possible yet equally unpleasant consequences. The unleashed spirit can inflict health problems on the affected individual. Even today in the societies of East Asia influenced by Ancient Chinese Culture, one is struck by the emotional restraint among the people. That may well be an aftereffect of the idea that emotional exuberance is a prime cause of illness.

Zheng 正, xie 邪: At least as important for the assessment of an inner "depletion" as a condition that endangered one's health was an experience from the time of the Warring States that began to be used in concepts of pathology at this time. Wherever a state of depletion arises, it is immediately exploited by neighboring forces that penetrate from their own territory. Everything that is located where it belongs is "righteous" or zheng 正. Everything that leaves its proper place and exploits “depletion" xu 虛, in another place and goes where it does not belong is evil or xie 邪. This juxtaposition of "righteous" and "evil" introduced the two topics of the new attitude's view of sickness and health. On one hand, medicine provides a constant warning to behave "righteously" in every respect, i.e., to perform one's duties where one belongs, for anything else would be evil. The value judgments used here apply, it was believed, both within nature and society.

On the other hand the idea of "evil" established an alternative to possession by demons. It was no longer the demons that are evil, the evil that afflicts humans. It became natural phenomena such as wind, moisture, heat and cold, which were considered "righteous" as long as they carried out their natural functions outside the human body; yet the moment people exposed themselves by opening a "depletion" in their bodies, in the moment that "righteous" natural phenomena exploited this "depletion" and penetrated a body they had no business in, that was when these phenomena became "evil" and had to be driven out. But it was not only intruders from outside the body that could take advantage of depletion. The organs themselves played the same role in the organism that the individual kingdoms played for centuries during the Warring States period. Any vulnerability in a neighboring territory resulted immediately in an invasion. The organism mirrored this condition. If any organ's resources, i.e., its qi, became excessively depleted, then qi from a neighboring organ would invade something that, depending on the relative power of the organs in question, had health consequences that were more or less serious for the individual.

The new medicine therefore pledged that whoever behaved "adapted," shun 順, and "righteously," zheng 正, in the right place, whoever bridled their emotions and therefore kept the spirits in check, as well as shielding their inner structures from external attack, had attained existential autonomy within the possibilities of biology, i.e., nature. The opposite behavior, of ni 逆 or violation of the laws, and an attack on foreign positions, xie 邪, would be punished just as strictly as the culpable depletion of one's own resources, which allowed alien forces to take over the weakened terrain, cheng 乘. The terms were always the same, regardless of whether the subject was one of conduct toward one's own body in nature or the behavior of society. People know what to expect when they behave this way or that. The new Chinese medicine was a profoundly holistic, comprehensive healing art. It merged the individual body and the politics of society in the closest manner possible.

\section{The holism of politics and medicine}

This holism is still expressed as another legacy of the Warring States period, which lasted for centuries, ended with the unification of China in $221 \mathrm{BCE}$ and whose traumatic effects linger into the present day. As all social philosophers of the time agreed, human society yearns for ping 平, or peace; an 安, or “security", and he 和, which is "harmony". These conditions seemed very distant during the time of the Warring States and, even since then, have become reality in China for only short periods at best. Little wonder, then, that the new medicine should have promised to implement this desire, at least within one's own body, or that the utopia of social harmony has to this day remained a political buzzword with an exceedingly high standing in China. Reaching this social and political goal requires adjustment, or 
tiao 調, among rival groups and regions; it leads ultimately to order, zhi 治.

Like the Su Wen, the Ling Shu does not have a discrete term for "health". There is a concept of "normal" people, with certain bodily and skeletal measurements that are laid out in chapter 14, and whose physiology, especially in the act of breathing, follows very certain sequences and schedules, which are described for example in chapter 15. People, however, are not equal, which is why chapters 64 and 65 identify the characteristics of 25 types of people. The ideal condition of the "healthy" individual is ping 平, i.e., peace, or he 和, meaning harmony. This condition is reached through "adjustment," tiao 調, among the rival forces in the body. These are first and foremost the yin and yang qi, which are forever trying to exterminate each other and therefore keep seeking revenge as well. Therefore, as the unnamed author stresses in the Ling Shu, chapter 33:

"Knowing how an adjustment can be achieved is useful. Not knowing how an adjustment can be achieved is harmful".

Therapy is therefore a matter of ordering, of governing, or zhi 治. As if Huang Di had needed a bit of tutoring, in chapter 45 his dialog partner Qi Bo wishes to recapitulate the parallels identified in chapter 29 between state order and physical health. And when Huang Di immediately interrupts him with the words, "I would like to be instructed in the WAY of using the needle, not about affairs of state!" Qi Bo replies that the one is not possible without the other: the WAY, or dao, is identical with that of managing a state.

Order, zhi, is opposed by disorder. Several terms in medicine were taken from the colloquial language for the concept of sickness, being ill and suffering: bing 病, ji 疾, huan 患 and ku 苦. Yet the real opposite to zhi, "order", is considered to be luan 亂, or "disorder". Fear of luan, of social disorder, continued to echo long after the trauma of the Warring States period and thereby also became the umbrella term for illness, both in society and one's own body. The political medical holism of Chinese medicine was the most important guarantee that this healing art should have achieved such a long continuity as an integral element of the Chinese Empire's political culture. The problem of translating terms as centrally significant as zhi and luan into a Western language also makes clear that a classical, let alone authentic, rendering of Chinese medicine is impossible in European culture. By translating the terms zhi and luan in a political context into "ordering/governing" and "social disorder", and in a medical environment as "treating/healing" and "illness", we dissolve the most important conceptual trait of Chinese medicine and relegate it to the exclusive sphere of the healing arts, a seemingly irrelevant area for society.

\section{Morphology substrate and classification}

In the Ling Shu and Su Wen the terminology and concepts of the individual body and the body politic the state are largely identical. The new medicine offered not only a new approach for dealing with individual healthy and sick bodies. It also embedded this approach within a very definite social order. The bureaucracy essential for the functioning state appeared in the body as well. In chapter 8 of the Su Wen, one umbrella term for the actors in the body that we call organs is guan 官, “administrator" or "official". Just as in English the anatomical term "organ" was applied to the state and its "organs", in Chinese Medicine the process was reversed: the bureaucratic term guan was applied to the "administrators" in the body. In the Ling Shu the term guan is used differently. There, the eyes are the administrator of the liver, the nose is the administrator of the lung, the mouth is the administrator of the spleen, the tongue is the administrator of the heart and the ears the administrator of the kidneys.

In the secular view of the world, all phenomena are either yin or yang. The same applies to the organs. In both the Ling Shu and Su Wen, the yin yang theory is applied to the subdivision of the entire body and its functions and, therefore, the organs themselves. Some lie deep inside the body and are dedicated to the long term storage of resources: the lungs, heart, spleen and kidneys. They bear the designation zang 藏, “long term depot”. Then there is a second group, the large and small intestine, stomach, gall bladder, bladder and a never exactly defined, so called triple burner. These organs receive their stores today and relinquish them again tomorrow. These are the fu 府, the "shortterm repositories".

The meaning of fu changed at the end of the Warring States period. The definition "grain repository" or "granary" was replaced by "administrative building" and, finally "palace". At this point the designation of the "wind palace", feng fu 風府, becomes understandable: an opening through which the wind preferentially enters the body. However, there was also a small misunderstanding documented in one of the dialogs between Huang Di and his adviser Qi Bo in chapter 79 of the Ling Shu. The former believed that there is only one wind palace in one particular place, namely in the nape of the neck behind the upper end of the spine. The latter corrected Huang Di in that, during malaria, the wind palace permits evil to enter at the level of a different vertebra every day. Otherwise in the Ling Shu, the term fu designates only the "short term repositories" in contrast to the "long term depots" among the organs. During the united Chinese Empire and even earlier, when the last separate kingdoms had grown into huge political entities, granaries as long term depots of grain as basic nutrient had become essential for feeding the population all year long. They had the same significance for the physiology and pathology of the human organism.

Objections have been raised in the past to translating the Chinese terms for the lung, heart, liver etc., as such. According to this argument, ancient and historical Chinese medicine associated completely different functions and structural classifications with these organs than e.g., Western medicine does. Regarding the eyes as a continuation of the liver, for example, seems quite alien to the European viewpoint. And yet, this argument is not persuasive. The morphological identification of the organs in ancient Chinese texts such as the Ling Shu, the Su Wen and the Nan Jing is, without any doubt, largely identical with the morphology of the organs as it was known in Europe as well since ancient times. An excerpt from chapter 12 of the Ling Shu illustrates this quite clearly:

Let us take a male person of eight feet height as an example. He has a skin and he has flesh. His outer appearance can be measured. His structures can be followed and pressed with the fingers so as to locate them. Once he has died, he may be dissected to observe his interior appearance. Whether the long term depots are firm or brittle, and whether the short term repositories are large or small, how much grain they have received, and of what length the vessels are, whether the blood is clear or turbid, and whether the qi are many or few, whether the twelve conduits transmit much blood and little qi, or little blood and much qi, and whether overall they contain much blood and much qi or little blood and little qi, all this can be quantified.

Location, capacity, size and other parameters are described with precision in the Ling Shu. Especially chapters 32 and 49 provide this information. The term xin 心 does cause some difficulty. It can mean 
both "heart" and "stomach". Otherwise, "lung" is the lung and "liver" is the liver. The difference lies essentially in the attribution of functions and in the presumed inner relationships. Interpreting the heart and small intestine as a pair in the same manner as the liver and gallbladder is alien to European thinking. Yet these differences do not justify the avoidance of literal translation. Otherwise, it would also be impermissible to translate the Chinese for "ears" as ears and the Chinese for "nose" and "mouth" as nose and mouth, for their physiological functions and structural relations within the organism are likewise partly alien to European thinking.

This also applies to the abovementioned concept of blood. The substance of 血 xue is the same as that of haima in Ancient Greece and of blood in our everyday and specialized medical understanding of it. It is the vital substance that flows through the body, can coagulate within the body, flows out of the body during nosebleeds, menstruation and injury and which must be conserved. Blood is blood. Interpretations, however, of how blood is made, what purpose it has, where it flows and more, were different and even in $19^{\text {th }}$ century English texts no longer corresponded to the state of our knowledge. Still, we always called it "blood".

In both Ancient Greece and the ancient texts of Chinese medicine, the concept of "blood" as a visibly red bodily fluid contrasted with that of the invisible yet equally essential vapors. The ancient Greeks called these aer or pneuma, and referred to the "arteries", literally translated as "air vessels", since the arteries appear empty when a corpse is dissected. The authors of the ancient Chinese texts regarded the matter somewhat differently. Only the blood is bound to vessels, they thought. Blood that stagnates outside of the vessels following injury through blows or impacts was a pathological sign. On the other hand, vapors the aforementioned qi can make their way anywhere in the body. They enter the body through food and drink, as well as via the air inhaled through the mouth and nose. They can leave the body through the mouth and nose, through the skin and also, for example, as flatulence.

The difference in mobility of blood and qi was reflected in classifications of yin and yang. Blood is yin and the qi are yang. Blood is classified as yin because of its material weight: blood flows downward. The yang classification of qi is due to their lightness and literal intangibility: They spread out in all directions and are therefore yang.

The authors of antiquity imposed a second categorization on top of these groupings. They believed that the body has a defense system with both yin and yang component. They named these two components corresponding to our ideas of "defense" using military terms. The yin components were ying 營, or "military camps", the yang components wei 衛, literally "guards" which can patrol freely. Ying and wei, camps and guards, are qi as an umbrella term; the blood was equated with military camp qi, i.e., as sentries fenced inside a camp, just as the blood is fenced in by the vessels. They are bound to certain locations and therefore yin in character. The qi in the more restricted sense was equated with the guard qi. Their mobility is a trait of yang, which can patrol both in the inner and outer areas of the body, always on the alert to identify and battle intruders. The term bo, "to strike at", is the most common expression in the Ling Shu for the encountering of mutually hostile qi.

\section{The causes of illness}

The causes for a person's illness were in no way one dimensional and definitely not simplistically presented in the Ling Shu. Not least in light of the Ling Shu's broad and seemingly modern etiological palette, we must again ask: where does all this experience come from, given that the Chinese sources offer no hint of an extended period in which, this knowledge could have developed? Perhaps one should keep in mind that the one or two centuries between the end of the Zhou and founding of the first Han dynasty and the probably writing of much of the Su Wen and Ling Shu were no less creative a period than the two hundred years between 1800 and 2000 in Europe. It was a long time, and in this long time much was conceived, applied and transformed into experience and knowledge. This may well also have been so in Ancient China. As the content of the Su Wen and Ling Shu demonstrate again and again, their authors were intellectuals of a high order, and we can assume that their thinking was as fruitful and incisive as that of their counterparts two millenniums later.

Sickness, as they recognized, is a highly complex matter. Sickness is unwanted and must therefore be fought in two respects: first, because it is already there; and second, before it can affect a person in the first place. Just like European medicine in the time before antibiotics, Chinese medicine sought primarily to prevent sickness from emerging in the first place. The best known and oft cited remark on this concern can be found in chapter two of the Su Wen: "The sages did not treat those already ill, but treated those not yet ill. They did not govern what was already in disorder, but what was not yet in disorder. Now, when drugs are employed for therapy only after a disease has become fully developed, when [attempts at] restoring order are initiated only after disorder has fully developed, this is as if a well were dug when one is thirsty, and as if weapons were cast when the fight is on. Would this not be too late too?

The fundamental idea that it makes sense for the individual to make proper life choices and for the medical practitioner to prevent a manifest illness through prompt intervention is found repeatedly in the Ling Shu. A passage from chapter 55 immediately parallels the above-cited excerpt from the Su Wen:

"The superior practitioner initiates a cure where there is no disease yet; he does not cure where there is a disease already".

To reach this goal, however, one must first know the origins of disease. And the variety of these causes did not remain obscure to observers of the time. In keeping with the tenets of the new view of the world, first all non natural causes of illness were excluded. "Heaven," as was repeatedly stressed, is absolutely neutral. It cannot be blamed for anything.

A detailed discussion is dedicated to this idea in chapter 58 of the Ling Shu. In one of the most remarkable dialogs of the entire text, Huang Di asks many questions on the relationship between external pathogenic influences and as we would call it today psychological condition of people on one hand and their illness on the other. Each time he is enlightened by the clear words of Qi Bo. The conversation finally ends with the doubts of Huang Di:

"When someone has never encountered evil qi, and has no fearful mind, and suddenly falls ill nevertheless, what is the reason? Could it be that [he falls ill] because of the workings of demon spirits"?

This question might also be asked today by someone not entirely convinced by purely secular explanations for all the events and processes of life. Qi Bo responded:

"This, too, is because old evil [qi] have remained [in the body], without having broken out [as a disease]. When someone has an aversion to, or excessively longs after something, his blood and qi will be 
disturbed internally, and the two qi beat at each other. The origins are quite subtle. One may look at them, but will see nothing. One may listen to them, but hears nothing. Hence it seems as if demon spirits were involved".

One might ask whether in our time, two thousand years later, one could give a better answer to Huang Di's question. Yet Huang Di is not yet convinced and points out that sometimes patients are healed after a prayer is said. Qi Bo then instructs him that those who say such prayers already know in advance which temporal and other circumstances overcome an illness, and if they also know how the illness arose they can put two and two together and say a prayer that allegedly brings about the healing.

In chapter 60 of the Ling Shu Qi Bo saw himself compelled to use strong words. Obstruction and impediment illnesses are discussed there. These are blockades of the bodily conduits through which the blood and qi flow. These "obstructions" and "impediments" finally lead to abscesses, carbuncles and similar lesions, as the blockaded blood and qi rot when they cannot flow, and then break out through the skin above. Qi Bo used this explanation to stress once again the emergence of this and some other illnesses from within the organism:

"Now, the emergence of obstruction and impediment illness, and the formation of purulent blood, that is not something sent down by heaven, and it does not come out of the earth. It emerges from minimal accumulations".

One can almost watch him gradually lose his patience at having to explain such elementary matters to his listener.

Demons and spirits can therefore be completely excluded as causes of illness. The alternatives introduced by the new medicine covered a broad spectrum. They stretched from the processes and changes of life, one's innate constitution, hazardous climatic conditions, effects of social status and one's regional life center to individual living conditions and emotional agitation. A passage in chapter 28 says:

"As for the very first origin of all diseases, they all originate from wind, rain, cold and summer heat, from yin and yang [qi], joy and anger, from beverages and food and from living conditions, from being severely scared and from sudden fear."

Of course, one's own responsibility for making life choices that maintain health is first and foremost. This was the foundation of existential responsibility, of living a life "adapted" to the laws of nature and not "violating" them.

The individual is surrounded by natural phenomena that apparently simply await their chance to gain entry and then cause illness. He must therefore refrain from exposing himself, i.e., granting them a breach from the outside through which "evil" could then enter his body. As we have seen above, it is the emotions that, when excessively developed, create the space or "void" that then invites the intruder to invade. In its normal state the skin is a closed barrier to prospective intruders. It must be overcome, for example through structures such as sweat pores that open up following great exertions, thereby providing an entry route. Especially the wind, originally perceived as a powerful spirit, has since ancient times been identified as the first of the natural forces that have no place inside the human body, yet gain entry through inattentiveness and then, often together with cold or moisture, cause blockages in the flow of blood and qi, causing pains, swelling and many other symptoms.

The observers of the time also recognized that sickness or health depended not only on the choices one makes in life. Evidently there were innate constitutions that gave some people long lives and others an early death. One person, we read in chapter 47 of the Ling Shu, is born with a large heart, another with a small heart, one with a large kidney, the other with a small kidney, etc. It is completely clear, according to the author, that these innate constitutions lead to differing chances in life.

As we learn in chapter 50 , the innate constitution is much more important than one's mental composure when it comes to how well one endures pain. It makes no difference whether one is courageous or a coward; there are individuals of both types who can bear pain and some that cannot. It does not depend on a deliberate choice, but is already spelled out by one's inborn constitution. Here we can also note an amusing detail that would come to light when discussing, in today's terminology, the loss of impulse control. Why, as we read in chapter 50 of the Ling Shu, do some cowards sometimes nevertheless take on courageous men? Because they are drunk, according to the explanation then and now; because alcohol lowers one's inhibitions.

The question of why one person lived long despite being exposed to the greatest dangers, while another died young who kept a quiet existence within his four walls and lived an "upstanding" life, is discussed from various angles, for example in chapter 54 . In chapter 58 the question is explored of how someone can fall ill without any apparent external pathogenic influence. All this is largely comprehensible, yet some of the ideas at the time on the origins of illness remain limited to Chinese medicine. In the Ling Shu this is especially the interpretation of certain seasons and days as especially hazardous to health. These concepts might reflect observations that had a certain empirical basis in China, as until recently, at least, the country had a continental climate in which seasonal climatic processes could be quite precisely dated and were therefore predictable. However, the systematization of such experiences and their association with the theoretical framework of the yin-yang and Five-Phase doctrine remain hardly understandable to present-day readers.

\section{Diagnosis}

The Ling Shu and Su Wen document a highly significant advance in the evaluation of illness. They explicitly and repeatedly introduce a differentiation that apparently had not previously existed, namely distinguishing between the pathological condition that arises inside the organism and which can be ascertained using only theory on one hand, and the pathological consequences of this condition, which in some respects manifested themselves to the patient as unpleasant changes but indicated deviations from normal conditions to the practitioner. The new medicine made use of a series of comparisons to draw attention to these deviations. The "root", or ben 本, meaning “origin" and its opposite: "end", mo 末, meaning "consequence", was one of the conceptual pairs with which illnesses and symptoms were referred to.

It is up to the healer, using diagnosis to identify the "root" of an illness and draw necessary conclusions for therapy or, given an unfavorable prognosis, for the non introduction of therapy. In ancient cultures this differentiation could decide between life and death of a healer, of distinguishing those who were incurably ill and therefore could not be treated. A doctor who treated an incurable patient was either incompetent or intent on profiting from someone sure to die. Both of these were reprehensible and possibly criminal. Therefore the prognosis played an important role both in Ancient China and Greece. There are no comparable ancient sources for Indian Ayurveda medicine, but there, too, until the arrival of modern Western medicine the Ayurveda 
doctor had to exercise extreme restraint toward the incurably ill and therefore depended on proficiency in devising a prognosis.

Diagnosis itself is subject to a hierarchy in the Ling Shu. In chapter 4 we read that those who need only to look at patients to recognize their health problems are "enlightened", or 明 ming. The designation for the second highest competence that healers who need to feel the pulse can attain is a striking one. These individuals are merely "divine", 神 shen. One might think that the "divine" would tower above all else. Yet that is precisely what the author of this text avoided expressing. The "divine" here is not to be associated with "gods" in the numinous sense; it simply means "prominent", not even "very good": that was reserved for the enlightened ones. The idea of the "divine" was downgraded here the same way as when one calls something divine in English (or in German as göttlich): One could just as well say "wonderful" or "fantastic". It has nothing to do anymore with the deity venerated by a religion. At the bottom of the ranking is the healer who has to ask the patient questions. Anyone depending on that was merely a practitioner, $工$ gong.

The special esteem for the mere observation of a patient as the basis for an exact diagnosis might seem astonishing. However, it had a quite concrete background. Let us go back to the very first reference to a doctor patient relationship in the history of Chinese literature. It was an encounter recorded in the Shi ji 史記 by 司馬遷 Sima Qian in about 100 BCE, of 扁鵲 Bian Que and the Marquis Huan of Qi. Bian Que took part in an audience of the sovereign and noticed from a distance that he needed treatment that could still heal an illness in its early stages. However, when he raised the matter he was harshly rebuffed. The story had a sad end, as the Marquis refused to take even subsequent warnings seriously and was eventually no longer curable. Besides being the oldest known doctor patient relationship in China, it also shows how difficult it is for a doctor to approach a ruler. The Ling Shu refers to this problem repeatedly and most clearly in chapter 29 . It is nearly impossible to convince rulers and other lofty individuals to submit to a detailed, personal examination of their bodies. Touching them, for example to take their pulse, is virtually unthinkable. The only way to examine such people when they are suffering is from a due distance.

The Ling Shu offers many diagnostically relevant parameters that inform the observer about a patient's inner condition. According to chapter 4 of the Ling Shu, the correlation between the inside and outside is as immediate as the striking of a drum and the sound the drum emanates, and especially as characteristic as the relationship between an object and its reflection in clear water. Of primary importance are complexions, especially in the face, to the right and left of the nose, under the eyes and in other telling places, such as the fingernails, where a yellow color, for example, would indicate a problem with the gall bladder according to chapter 47. Correspondences laid down in the five phase's doctrine between externally recognizable colors and internal organs provide essential insights for a subsequent treatment. Certain other features also yield key information.

Whether the eyes are large or small tells the observer something about the gall bladder. The condition of the lips yields information about the spleen. Whether the patient has to raise his or her shoulders to breathe says something about the lung. The size of the skeleton, dimensions of the nape, the expansion of the rib cage indicate the condition of the stomach and diet. For all of the short term repositories and long term depots there are "indicators" on the body's exterior that the observer must note in his diagnosis. The height of the nasal bone, the size of the nostrils, the bags under the eyes all these facts told the keen observer something about the condition of his subject, without even having to touch him or hardly conceivable with a high ranking individual interview him. Yet there is also a conscious change of perspective. In chapter 74, Huang Di demands exactly the opposite of Qi Bo. He did not want to inspect complexions or investigate the flow in the vessels of various body parts. Instead, he wanted to know how one could recognize something about an illness merely by examining the condition of one place on the wrist.

The instruction that Qi Bo gives him illustrates that transition from visual and tactile inspection of the vessels of the wrist and the surface of the skin above them to the inspection of movements in the vessels. A term commonly used until quite recently in Chinese medicine for feeling the pulse is kan mai 看脈, literally "observing the vessels". When Qi Bo refers to the diagnostically relevant conditions of a certain section of the wrist as "slack or tense", "minimal or enlarged", or "smooth or rough", the boundaries between the perception of these values of the skin or as characteristics of the movement in the vessels are obfuscated. Whether the vessels are "diminished" or swollen as the result of obstructed blood and qi must likewise be included in the evaluation of an illness.

\section{Condition of illness}

The maladies discussed in the Ling Shu are associated mainly with xie qi 邪氣, or “evil qi". They can enter the body from the outside as wind, cold, warmth, heat or moisture. Once inside they remain static in one place or they move farther inside, from the skin to deep in the long term depots and even the bone marrow. A third possibility is that they are transported from one long-term depot to another. Of the kinds of evil qi that enter the body, one distinguishes between "proper evil", zheng xie 正邪, and xu xie 虛邪, or “depletion evil". The former are climatic qi determined by the seasons, such as heat, cold, etc., which are basically "proper", zheng 正, because they appear during the appropriate season. They are nonetheless "evil" because the enter the human body uninvited. "Depletion evil", on the other hand, is in the wrong place from the start. They are e.g., the heat that comes in winter instead of summer that then penetrates the body. "Proper evil" and "depletion evil" can cause differing diseases. The illness here generally takes on an ontic character. It is manifestly present, can be localized and even touched by the fingers and, by the means identified in the section on therapy, can be physically removed.

"Depletion evil" and "proper evil" are opposites. "Depletion" and "repletion" are another. Again and again in the Ling Shu, we find the command to fill depletion and to empty repletion. This partly does mean "too much" of something as opposed to "too little", especially of qi. But it also has another meaning, when depletion is considered a lack of proper qi and repletion the presence of evil qi. Once wind and cold have entered the vessels, they can block the flow of blood and qi; such blockages are the most common cause of pain, swelling and also the aforementioned obstruction and impediment illnesses, which in turn can cause abscesses, carbuncles and other lesions.

The clash of evil qi and guard qi produces its own effects. These are influenced by a seeming contradiction. Chinese medicine has a concept in which the blood and qi circulate through two separate systems of conduit vessels on both the left and right halves of the body. In both the Su Wen and Ling Shu, this idea competes with another one saying that the individual sections of the conduit vessels, which are assigned to the three different yin gradations (major yin, minor yin and receding yin) and the three different yang gradations (major yang, 
minor yang and yang brilliance), are filled with differing proportions of blood and qi.

The dialogs often serve to explain general symptoms of illness on the basis of these concepts. In doing so they refer back to the fundamental doctrines of the secular natural laws of systematic correspondences. These are the yin yang and Five Phases doctrines. Neither is explicitly explained as such, the way they occasionally are in the $\mathrm{Su}$ wen. One example is the basic idea of a normality of force in both nature and the individual organism, of which chapter 69 of the Su Wen has the following to say: zhe bing,

气相胜者和不相胜者病 qi xiang sheng zhe he, bu xiang sheng

"When the qi subdue one another, this is harmony. If there is no mutual subduing, this is disease".

In the Ling Shu one finds hardly any such general statements about the nature of yin and yang. They become apparent, instead, in their application. The doctrine of the Five Periods and Six Qi, wu yun liu qi 五運六氣, a segment of some 30,000 characters probably inserted into the Su Wen by Wang Bing 王冰 in the $8^{\text {th }}$ century, yet which we believe existed already during the Han period, is only marginally referred to in the Ling Shu, e.g., in chapter 79. Even more than the Su Wen, therefore, the Ling Shu gives the impression that its authors presumed familiarity among readers of the doctrines of systematic correspondences. Consequently, most of its explanations on illness and the physiological and pathological processes in the human organism consist of explanations obviously based on this presumption.

Entire chapters are dedicated to these explanations. In some dialogs, maladies identified in colloquial language and felt or observed by laypersons are directly subjected to theory, e.g., in portraying the spread of illness within the body. Often theory can be identified only indirectly in statements regarding therapy. The conduit segments or other body areas selected for acupuncture or bloodletting indicate what yin or yang regions were associated with an illness. One example s chapter 24 of the Ling Shu. This chapter is one of the few written as a normal, narrative text instead of a dialog.

The first part of the chapter consists of various elaborations on treating "headache" and then "pain in the heart" that arise from "receding qi". How these symptoms come to be, or why qi recedes, is not explained. Headache that arises from "receding qi" may be accompanied by a "swollen face and vexed heart" or a "grievous heart" and "tendency to weep," thereby requiring differing procedures that would show the specialist where the problem theoretically lies, e.g., in the "foot yang brilliance" or the "foot major yin conduit". Headache resulting from receding qi may be associated with dizziness or forgetfulness or joint pain. All these variations of headaches are attributed in theory to the presence of evil qi in various parts of the vessels and require accordingly differentiated therapies.

Numerous health problems are discussed, from discomfort in swallowing and deafness, from nosebleed and menstruation discomfort to digestion problems and tapeworms, psychological problems and tumors. Explanations of illness symptoms distinguish between those sophisticated enough to be mentioned in specialized literature and those that were only passed on orally. In chapter 28 of the Ling Shu these include explanations for everyday inconveniences such as "yawning," "sneezing", "deep breathing", "noises in the ears" and others, including biting one's tongue accidentally. For all these phenomena Huang Di asks about, theory in the words of Qi Bo offers an explanation. In chapter 32 Huang Di asks why a person who does not eat will die after seven days. Qi Bo then identifies the size and capacity of the stomach and intestines, calculates the amounts of daily intake and daily discharges and deduces when the supplies to the organism will be exhausted. Chapter 43 is dedicated to dreams, the various contents of which indicate where in the body abnormalities are occurring. Chapter 81 is devoted to the many abscesses and other skin problems caused by "obstruction and impediment illnesses".

In its entirety the text gives the impression that the authors strived to make all health problems that confronted the people of the time comprehensible within their secular explanatory model based purely on natural laws. Only the comprehension, we read, makes successful treatment possible.

\section{Therapy}

Starting therapy without thorough diagnosis is rejected and attributed only to "unrefined" practitioners. Therapeutic procedures to be used for treating a patient are multiple and can hardly be grasped competently by one healer alone.

The authors of the Ling Shu knew that a medical treatment could not be some kind of mechanistic repair. Chapter 29 of the Ling Shu therefore spells out how important it is to find out what patients want and what would help them. The author uses comparisons to make the point.

"One enters a [foreign] country, and enquires about its customs. One enters [someone else's] household, and enquires about their taboos. One enters [someone's ancestral] hall and enquires about the rites to be observed. One attends to a patient and enquires about what will ease his condition".

We can read between the lines that the patient's mental expectations and emotional needs greatly influence the therapy's success. Therefore, treatment must incorporate the patient's social environment into the therapy instead of regarding the illness in isolation. High ranking individuals are both approached differently in their diagnosis and receive a special, perhaps less aggressive therapy. Where the average patient would be treated with "fire", i.e., cauterization, loftier clientele are given gentle compresses to bring the required warmth into the body. This differentiated approach is discussed especially clearly in chapter 5 of the Ling Shu:

\section{Huang Di question:}

Now, kings, dukes, and eminent persons, gentlemen who consume bloody [meat], their body is soft and fragile, and their muscles and flesh are gentle and weak. [The flow of] their blood and qi is swift and vigorous, smooth and unimpeded. Is it at all possible that when piercing them, whether an insertion is slow or fast, shallow or deep, often times or few times, could be identical with [the treatment of normal persons]"?

\section{Qi Bo answered:}

"How could rich food and coarse vegetables be identical?! If the [flow of] qi is smooth, the needle is to be removed quickly. If the [flow of] qi is rough, the needle is to be removed slowly. If the [flow of] qi is vigorous, then the needle must be small and it is to be inserted superficially. If the [flow of] qi is rough, then the needle must be big and it is to be inserted deeply. A needle in the depth is to remain there. A needle at the surface is to be removed quickly.

Looking at it this way when piercing normal persons the needle is to be inserted into the depth and is to remain as it is. When piercing 
eminent persons, the needle is to enter the skin only a little, and is to be withdrawn quickly. This is so because it is always such that the flow of the qi of the latter is swift and vigorous, smooth and unimpeded.

The procedures ultimately executed by the expert use acupuncture first and foremost. Needles might be as fine and supple as a hair and penetrate into the organism to a greater or lesser degree. The Ling Shu includes a list of the nine varieties of needles right in the first chapter. They might be heated and inserted directly on the painful area, for example when used on strained sinews accompanied by severe pain, fast breathing and spitting blood. They might also be needles with a ball shaped end, so that they clear a path by pushing structures aside without doing damage when they are inserted.

They might also be sharp blades used with the opposite intention, namely of opening the skin to drain pus or open the vessels to let blood. The "removal", qu 取, of blood is a therapy connected to the ontic view of the illness, one that is often recommended in the Ling shu. The illness is removed along with the blood, according to the text. There may have already been skeptics in antiquity whether these little needles were really as important as the new medicine claimed. A question to this effect is asked by Huang Di, and Qi Bo makes some emphatic comparisons to confirm the needles' significance. The most important position in nature is occupied by man. Weapons are used to kill him in war. To save his life, medicine uses the little needles:

"Huang Di: For me the small needles are insignificant items. Now you say that above they are united with heaven, below they are united with the earth, and in the middle they are united with mankind. To me this seems to greatly exaggerate their significance! I wish to be informed of the underlying reason".

"Qi Bo: Is there anything bigger than heaven? Now, what is bigger than the needles? Only the five weapons. The five weapons are prepared to kill. They are not employed to keep [someone] alive. Furthermore now, mankind! The most precious item between heaven and earth. How could it be neglected? Now, to cure the diseases of humans, only the needles are to be applied. Now, when the needles are compared with the five weapons, which turns out to be less significant?"

The common therapeutic approach in the Ling Shu describes a health problem and then recommends acupuncture or bloodletting from a particular vessel or at a defined part of the body. The text makes no mention of who decided upon these recommendations or when they were made. The authors describe how something should be done but generally offer little hint of the thinking behind the therapy that has yielded the given instructions. A brief example from chapter 26 of the Ling Shu illustrates this kind of information:

"Nosebleed; [to treat such a condition], one chooses the hand major yang [conduit for piercing the needle]. If it does not end, one pierces below the wrist bones. If it does not end, one pierces the hollow of the knee and lets blood there".

Other instructions for therapy issue from a more detailed theoretical discourse, as an example from chapter 28 of the Ling Shu shows: that?

"Huang Di: When a person is mournful and weeps, which qi cause

Qi Bo: The heart is the ruler among the five long term depots and six short term repositories. The eyes are the location where the stem vessels come together. They are the path the liquids take when they ascend. Mouth and nose are the gateways of the qi.

The fact is: When someone is mournful and grievous, then his heart will be excited. When the heart is excited, then all the five long term depots and six short term repositories will sway. This swaying affects the stem vessels. When the stem vessels are affected, the pathways of the liquids will open. When the pathways of the liquids are open, tears will leave there. When the weeping does not end, then the liquids eventually will be exhausted. When the liquids are exhausted, the essence will no longer be moistened. When the essence is no longer moistened, then the eyes can no longer see. Hence that is called 'deprivation of the essence.' One supplements at the tian zhu [openings] on the conduits on both sides of the nape".

Explanations of what functions the individual conduits serve in the organism, which flows of blood and qi are normal and which is not, are found in a different part of the Ling Shu. Not infrequently, Huang Di listens to the remarks of his instructor to then respond with essentially the same words I have heard what you say, but I still do not know why that is so! This is then often followed by a more detailed explanation. Studying these remarks helps the reader to better understand the theory behind the instructions for treatment.

Acupuncture and bloodletting are clearly the primary therapeutic recommendations in the Ling Shu. The work is therefore considered the fundamental text on ancient Chinese acupuncture. It discusses the entire possible therapeutic spectrum of healing in terms of recommendations. Except for a handful of concrete recipes for preparing a medicine or compress, the text keeps to simply naming possible alternatives, of which the most detailed attention is devoted to cauterization. Massage and acupressure, medicines and compresses are referred to only a few times as sensible additions in cases when needling and bloodletting are too risky or ineffective. Chapter 19 discusses a veritable drainage to treat "water illness" using a bamboo tube. In chapter 24 the reader learns how to fix a tapeworm in place in the intestine and then to kill it with a long needle. Apparently the authors of the Ling Shu could assume that these kinds of procedures were familiar to readers. In chapter 26 three possible therapies for hiccups are listed which likewise require no theoretical background, being presented instead as the results of experience:

"Hiccup one pierces a blade of grass into the [patient's] nose so that he sneezes. Once he sneezes the hiccup will end. Or he holds his breath and quickly moves his face upward. The hiccup will end immediately. Or one severely scares the patient. That, too, may end [the hiccup]".

Basically, the Ling Shu is characterized by therapeutic optimism. Illnesses, as chapter one says, are like thorns, dirt stains, knots or closed places. The patient can thereby be cured just as thorns are pulled out, stains are washed away, knots untied and locks opened. Anyone who claims that a patient is incurable, no matter how long the illness has already lasted, is simply incompetent.

And yet there are limits. They are set not only by the recognition in the Ling Shu that this or that illness is incurable. The limits of treatment are also explained using explicit references to the rich experience of past military strategies. An acute illness is like an army in the field approaching with banners flying and drums beating. Attacking here is inadvisable. In chapter 55, Bo Gao established the parallels to the treatment of sickness:

"Bo Gao: In [the text] Rules of the Military it says: Do not confront those qi that come with a peng peng [rataplan]. Do not attack battle troops approaching with loud drum rolls. In [the text] Rules of Piercing it says: Do not pierce a baking heat. Do not pierce a dripping sweat". 
As one realizes from reading the Ling Shu, a competent practitioner's knowledge has to be comprehensive.

\section{About the translation}

This English edition of the Ling Shu includes the original Chinese text, a complete English translation and annotations from selected Chinese commentaries that help to better understand the content and identify variations in the text as they were handed down.

The original Chinese has been inserted in lines or sections into the English translation. Knowledge of Chinese is possibly quite common among readers of this translation and therefore I have aligned it as exactly as possible, not only in terms of content but also syntax, with the Chinese original. This ensures the highest level of transparency. Segments of the text introduced by me for a better understanding are marked by brackets: [xxx]. Also, I have rendered the Chinese with consideration for its content units and rhyme structures. Many passages in the Chinese were written in rhyming patterns of three or four or more characters each. The rendering of these rhymes sometimes reveals breaks, insertions or omissions in the original text and makes apparent from what diverse source texts the textus receptus of the Ling Shu was compiled. Characters or passages that Chinese commentators or I have suspected were erroneously inserted are identified by a gray background. Insertions that one may regard as latter day commentaries are identified in the translation within pointed brackets (> xxx $<)$. Longer passages that may have been introduced subsequently as additional information are identified in the translation within slashes $(/ / \mathrm{xxx} / /)$. These are all presumptions based primarily on structural comparisons and contexts.

The translation follows the same principles that I adhered to in my past renderings of ancient classics of Chinese medicine into English.
My primary effort has been to communicate the author's manner of thinking to contemporary readers by translating the terminology and especially the images as literally as possible. Again and again I have been encouraged in my approach not least by expectations that, through philological criteria comparably stringent to those long accepted in translations of the Corpus Hippocraticum, comparisons of ancient Chinese Medical texts with their European counterparts would be made possible.

This approach will offer hardly anything to those who do not take the ancient authors seriously. Reading their texts over the years has instilled the greatest respect in me. The longer one occupies oneself with their patterns of thinking and arguing, the clearer the intelligence becomes that they express. Therefore I have not followed the demands that are often voiced to essentially dispossess these people of their thinking and manner of expression by using modern terms and contemporary physiological and pathological concepts in the translation, as if asserting today that the authors of the time neither new nor understood what they were seeing in sick or healthy people and how to interpret what they saw. Back then they knew very well what they saw and understood it with great logic and reason in their time and with the means they had. This is what the present translation may suitably highlight.

\section{Paul U Unschuld}

\section{Reference}

1. Unschuld PU (2016) Huang Di Nei Jing Ling Shu: The Ancient Classic on Needle Therapy. University of California Press, USA. 